\title{
PENGARUH BAHAN BAKU DAN TENAGA KERJA TERHADAP PENCAPAIAN TARGET PRODUKSI DI SENTRA HOME INDUSTRI SONGKOK PENGANGSALAN LAMONGAN
}

\author{
Heru Dwi Prasetiyo ${ }^{1}$ \\ Fakultas Ekonomi Universitas Islam Lamongan \\ Email : heruprastiyo329@gmail.com \\ M. Rizal Nur Irawan ${ }^{2}$ \\ Fakultas Ekonomi Universitas Islam Lamongan \\ Email : rizalirawan@unisla.ac.id \\ Mohammad Yaskun ${ }^{3}$ \\ Fakultas Ekonomi Universitas Islam Lamongan \\ Email : m.yaskun@unisla.ac.id
}

\begin{abstract}
Abstrak
Penelitian ini di tunjukan untuk mengetahui pengaruh bahan baku dan tenaga kerja langsung terhadap pencapaian target produksi di Sentra Home Industri Songkok Pengangsalan Lamongan. Sampel penelitian ini yaitu pengrajin songkok Pengangsalan yang berjumlah 100 responden. Jenis penelitian ini menggunakan metode kuantitatif yaitu dengan menggunakan pendekatan dektriptif. Metode pengumpulan data dengan menggunakan SPSS. Bahan baku dan tenaga kerja langsung berpengaruh secara parsial terhadap pencapaian target produksi Di Sentra Home Industri Songkok Pengangsalan Lamongan. Bahan baku dan tenaga kerja langsung berpengaruh secara simultan terhadap pencapaian target produksi Di Sentra Home Industri Songkok Pengangsalan Lamongan.
\end{abstract}

Kata kunci : Target Produksi, Bahan Baku, Tenaga Kerja Langsung

\section{PENDAHULUAN}

Sejalan dengan kemajuan yang dicapai di sektor industri nasional maupun pada tingkat regional, perkembangan industri kecil di Kota Lamongan telah mengalami kemajuan yang cukup menggembirakan. Hal ini tercermin dalam peningkatan jumlah unit usaha, tenaga kerja, nilai investasi, nilai produksi dan nilai tambah yang dihasilkan sorta semakin berkembangnya jenis dan produk industri kecil di daerah ini.
Usaha industri kecil yang ada di pedesaan maupun di tempattempat lain, biasanya mengalami berbagai hambatan dalam menghasilkan volume produksi, sehingga pendapatan dari industri kecil juga menjadi rendah. Disamping itu industri kecil harus bersaing dengan

industri lainnya yang berskala besar maupun menengah. Hal ini menyebabkan terjadinya suatu persaingan yang tidak sehat. Industri yang besar memiliki 
modal besar dan teknologi canggih akan lebih mudah berkembang dibanding dengan industri kecil yang memiliki modal paspasan dan teknologi yang terbatas.

Industri kecil dapat berkembang apabila hendaknya dilakukan kerja sama antara industri kecil, menengah dan besar. Usaha kerja sama yang dilakukan baik sesama industri

kecil, menengah dan besar harus tetap diupayakan agar semakin meningkat. Hal ini akan dapat dilakukan dengan cara industri bcsar membantu pemasaran industri kecil atau dengan cara

memasok bantuan berupa bahan baku dan bahan pembantu serta alat-alat untuk meningkatkan produksi.

Pembinaan terhadap pengusaha industri kecil juga diarahkan pada masalah harga dan peningkatan kualitas produksi. Salah satu bentuk pembinaannya berupa konsultasi peningkatan mutu yang mencakup beberapa aspek dalam kegiatan dalam kegiatan produksi antara lain proses produksi, pemasaran, permodalan, kualitas perhitungan harga pokok serta administrasi pembukuan sederhana. Kegiatan produksi tidak akan terrwujud dan terlaksana tanpa adanya alat atau benda yang digunakan untuk memproduksi suatu barang. Dalam kegiatan produksi dibutuhkan tempat untuk produksi, peralatan produksi dan orang yang melakukan produksi. Benda-benda atau alat-alat yang digunakan untuk terselenggaranya proses produksi disebut faktor-faktor produksi. Jadi faktor produksi adalah setiap benda atau alat yang digunakan untuk menciptakan, menghasilkan benda atau jasa. Faktor-faktor produksi disebut juga sumber daya ekonomi, atau alat produksi yang meliputi faktor produksi alam, faktor produksi tenaga kerja, factor produksi modal dan faktor produksi ketrampilan. Selain faktor-faktor tersebut ada faktor lain yaitu bahan baku

Menurut Mulyadi (2014:275) bahan baku adalah bahan yang membentuk bagian menyeluruh produk jadi. Dalam menunjang suatu produksi juga tergantung juga pada tenaga kerja. Tenaga kerja meliputi tenaga yang bekerja didalam maupun diluar hubungan kerja dengan alat produksi utamanya dalam proses produksi tenaga kerja itu sendiri, baik tenaga fisik maupun tenaga fikiran.

Menurut (Murdinfin Haming 2014:35), Produksi adalah suatu kegiatan untuk menciptakan/menghasilkan atau menambah nilai guna terhadap suatu barang atau jasa untuk memenuhi kebutuhan oleh orang atau badan (produsen)

\section{METODE PENELITIAN}

Metode penelitian ini menggunakan kuantitatif. Yang menjadi Populasi dalam penelitian ini adalah Centra yang terdiri dari 266 pengrajin songkok di Desa Pengangsalan Kecamatan Kalitengah Kabupaten Lamongan. Yang dijadikan sampel dalam penelitian ini adalah 100 pengrajin songkok di Desa Pengangsalan Kecamatan Kalitengah Kabupaten Lamongan (Sugiono $2014: 81$ ) 


\section{METODE PENGUMPULAN DATA \\ Data Primer}

Merupakan data yang didapat dari obyek yang diteliti secara langsung melalui pengamatan objek seperti dokumen, catatan maupun arsip yang ada

\section{Data Sekunder}

Merupakan data yang diperoleh dari pihak lain berkaitan dengan permasalahan yang diteliti yang dapat menunjang hasil dari penelitian

\section{HASIL PENELITIAN DAN PEMBAHASAN}

\section{Uji Validitas}

Uji validitas digunakan untuk mengetahui kemampuan instrumen dalam mengukur variabel yang akan di ukur atau di teliti sehingga mengungkap data secara cepat. Pengujin validitas menggunakan Produt momen pada signifikan 95\% $(\alpha=0,05)$. Dengan cara mengkorelasikan masing-masing item dengan skor total. Dengan pernyataan dinyatakan valid, apabila skor item berkolerasi secara signifikan dengan skor yang ditunjukan dari nilai $r_{\text {hitung }}>r_{\text {tabel. }}$ Uji validitas dalam penelitian ini menggunakan mesin hitung SPSS 2.0 for windows. Dengan hasil penelitian untuk masing-masing sebagai berikut:

\section{Hasil Uji Validitas Variabel Bahan Baku $\left(\mathrm{X}_{1}\right)$}

\begin{tabular}{|c|l|c|c|c|}
\hline No & Indikator Pertanyaan & R hitung & R tabel & Keterangan \\
\hline 1 & Persediaan bahan baku & 0,872 & 0,2787 & Valid \\
\hline 2 & Pemakaian bahan baku & 0,897 & 0,2787 & Valid \\
\hline 3 & Biaya bahan baku & 0,922 & 0,2787 & Valid \\
\hline 4 & Biaya pemesanan & 0,916 & 0,2787 & Valid \\
\hline 5 & Biaya penyimpanan & 0,877 & 0,2787 & Valid \\
\hline
\end{tabular}

Sumber : data diolah, 2018

Hasil Uji Validitas Variabel Tenaga Kerja Langsung ( $\left.\mathbf{X}_{2}\right)$

\begin{tabular}{|c|l|c|c|c|}
\hline No & Indikator Pertanyaan & R hitung & R tabel & Keterangan \\
\hline 1 & Standar tenaga kerja & 0,384 & 0,2787 & Valid \\
\hline 2 & Biaya tenaga kerja & 0,625 & 0,2787 & Valid \\
\hline 3 & Upah & 0,724 & 0,2787 & Valid \\
\hline 4 & Tingkat penghasilan & 0,638 & 0,2787 & Valid \\
\hline 5 & Lingkungan kerja & 0,410 & 0,2787 & Valid \\
\hline
\end{tabular}

Sumber : data diolah, 2018

Hasil Uji Validitas Variabel Target Produksi (Y )

\begin{tabular}{|c|l|c|c|c|}
\hline No & Indikator Pertanyaan & R hitung & R tabel & keterangan \\
\hline 1 & Faktor produksi & 0,374 & 0,2787 & Valid \\
\hline 2 & Proses produksi & 0,657 & 0,2787 & Valid \\
\hline 3 & Tujuan poduksi & 0,670 & 0,2787 & Valid \\
\hline 4 & Bahan baku & 0,648 & 0,2787 & Valid \\
\hline 5 & Tenaga kerja & 0,434 & 0,2787 & Valid \\
\hline
\end{tabular}

Sumber : data diolah, 2018 


\section{Uji Reliabilitas}

Uji reliabilitas digunakan untuk menentukan sejauh mana alat ukur dapat dipercaya atau dapat di andalkan. Nilai reabilitas dapat diperoleh pada output perhitungan. Jika nilai reabilitas $>60$ maka dinyatakan bahwa instrumen yang digunakan sudah realiabel, begitu pula sebiknya.

Hasil uji reabilitas menggunakan program SPSS 2.0 For Windows sebagai berikut :

Hasil Uji Reliabilitas

\begin{tabular}{|l|l|l|l|l|}
\hline No & Indikator Pertanyaan & Item & Nilai Alpha & Keterangan \\
\hline 1 & Bahan baku & 5 & 9,40 & Realibel \\
\hline 2 & Tenaga kerja langsung & 5 & 6,38 & Realibel \\
\hline 3 & Target produksi & 5 & 6,03 & Realibel \\
\hline
\end{tabular}

Sumber : data diolah, 2018

\section{Analisis Korelasi Berganda}

dalam penelitian ini dihitung dengan menggunakan program SPSS 2.0 For
Windows. Adapun hasil analisis dapat disajikan sebagai berikut :

Hasil Uji Korelasi Berganda

\begin{tabular}{|l|l|l|l|}
\hline & $x 1$ & $x 2$ & $y 1$ \\
\hline Pearson Correlation & 1 &, $800^{* *}$ &, $679^{* *}$ \\
1 Sig. (2-tailed) & &, 000 &, 000 \\
N & 100 & 100 & 100 \\
Pearson Correlation &, $800^{* *}$ & 1 &, $681^{* *}$ \\
x Sig. (2-tailed) &, 000 & &, 000 \\
2 N & 100 & 100 & 100 \\
Pearson Correlation &, $679^{* *}$ &, $681^{* *}$ & 1 \\
y Sig. (2-tailed) &, 000 &, 000 & \\
N & 100 & 100 & 100 \\
\hline
\end{tabular}

\section{Uji Koefisien Determinasi $\left(\mathbf{R}^{\mathbf{2}}\right)$}

Uji determinasi pada intinya mengukur beberapa jauh kemampuan model dalam menerangkan variasi variabel dependen. Uji determinasi dalam penelitian ini dihitung dengan menggunakan program SPSS 2.0 For Windows. Adapun hasil analisis dapat disajikan sebagai berikut:

\section{Hasil Uji Koefesien Determinasi}

\begin{tabular}{|c|c|c|c|c|c|c|c|c|c|}
\hline \multirow[t]{2}{*}{ Model } & \multirow[t]{2}{*}{$\mathrm{R}$} & \multirow{2}{*}{$\begin{array}{l}\mathrm{R} \\
\text { Square }\end{array}$} & \multirow{2}{*}{$\begin{array}{l}\text { Adjusted } \\
\mathrm{R} \\
\text { Square }\end{array}$} & \multirow{2}{*}{$\begin{array}{l}\text { Std. Error } \\
\text { of the } \\
\text { Estimate }\end{array}$} & \multicolumn{5}{|c|}{ Change Statistics } \\
\hline & & & & & $\begin{array}{l}\mathrm{R} \\
\text { Square } \\
\text { Change }\end{array}$ & $\begin{array}{l}\mathrm{F} \\
\text { Change }\end{array}$ & df1 & df2 & $\begin{array}{l}\text { Sig. F } \\
\text { Change }\end{array}$ \\
\hline 1 &, $717^{a}$ &, 514 &, 504 & 1,04258 &, 514 & 51,204 & 2 & 97 & 000 \\
\hline
\end{tabular}

Sumber : data diolah, 2018

\section{Analisis Regresi Linier Berganda}

Analisis regresi linier berganda dalam penelitian ini dihitung dengan menggunakan program SPSS 2.0 For Windows. Adapun hasil analisis dapat disajikan sebagai berikut 
Hasil Uji Regresi Linier Berganda

\begin{tabular}{|c|c|c|c|c|c|c|}
\hline \multirow{2}{*}{\multicolumn{2}{|c|}{ Model }} & \multicolumn{2}{|c|}{ Unstandardized Coefficients } & \multirow{2}{*}{$\begin{array}{l}\text { Standardized } \\
\text { Coefficients } \\
\text { Beta }\end{array}$} & \multirow[t]{2}{*}{$\mathrm{T}$} & \multirow[t]{2}{*}{ Sig. } \\
\hline & & B & Std. Error & & & \\
\hline \multirow{3}{*}{1} & (Constant) & 8,022 & 1,673 & & 4,795 & , 000 \\
\hline & $\mathrm{x} 1$ & ,254 & ,080 & ,373 & 3,158 & , 002 \\
\hline & $x 2$ & ,381 &, 118 & ,383 & 3,241 & ,002 \\
\hline
\end{tabular}

Sumber : data diolah, 2018

\section{Uji Asumsi Klasik}

\section{Uji Normalitas}

Menurut Ghozali (2012:160) dalam model regresi variabel uji normalitas bertujuan apakah dependen dan variabel independen mempunyai kontribusi atau tidak.

\section{Hasil Uji Kolmogorov-Smirnov}

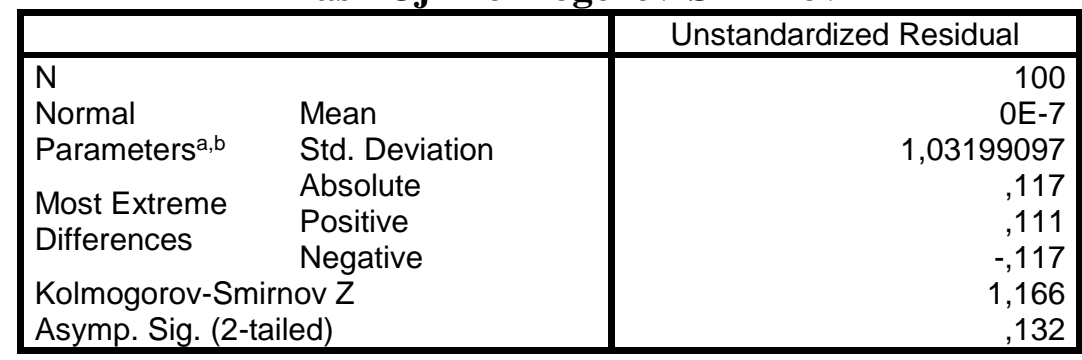

Sumber : data diolah, 2018

\section{Uji Normalitas}

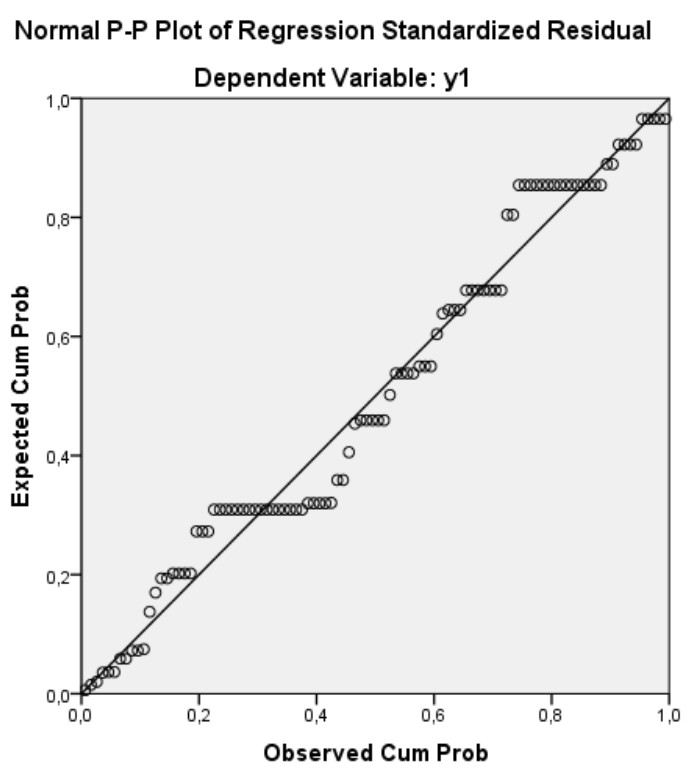

\section{Uji Multikolinearitas}

Menurut Ghozali (2012:105) uji multikolinearitas bertujuan untuk menguji apakah suatu model regresi terdapat korelasi antar variabel bebas (independen). 
Hasil Uji Multikolinearitas

\begin{tabular}{|c|c|c|c|c|c|c|c|c|}
\hline \multirow[t]{2}{*}{ Model } & & \multicolumn{2}{|c|}{$\begin{array}{l}\text { Unstandardized } \\
\text { Coefficients }\end{array}$} & $\begin{array}{l}\text { Standardized } \\
\text { Coefficients }\end{array}$ & \multirow[t]{2}{*}{$\mathrm{T}$} & \multirow[t]{2}{*}{ Sig. } & \multicolumn{2}{|c|}{ Collinearity Statistics } \\
\hline & & $\mathrm{B}$ & Std. Error & Beta & & & Tolerance & VIF \\
\hline \multirow{3}{*}{1} & (Constant) & 8,022 & 1,673 & & 4,795 & , 000 & & \\
\hline & $x 1$ & ,254 & ,080 & ,373 & 3,158 & ,002 & ,360 & 2,779 \\
\hline & $x 2$ & ,381 & , 118 & ,383 & 3,241 & ,002 & ,360 & 2,779 \\
\hline
\end{tabular}

Sumber : data diolah, 2018

\section{Uji Heterokedastisitas}

Menurut Ghozali (2012: 139)

uji heteroskedastisitas bertujuan menguji apakah dalam model regresi

terjadi ketidaksamaan varian dari residual satu pengamatan ke pengamatan

yang lain.

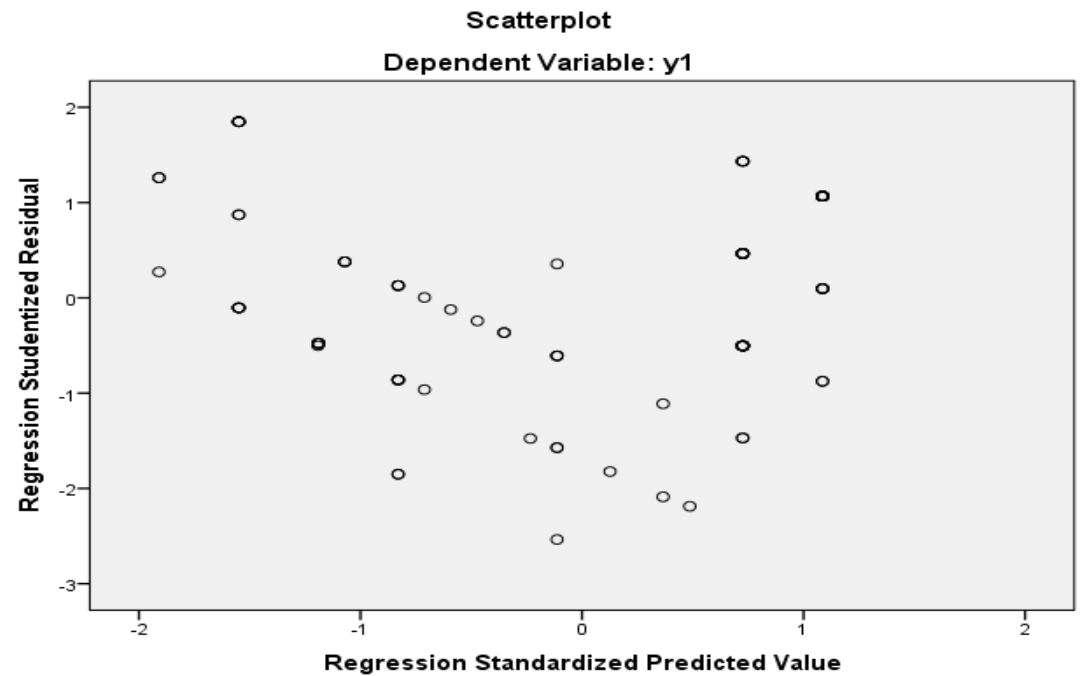

\section{Uji Autokorelasi}

Model Summaryb

\begin{tabular}{|l|l|l|l|l|l|}
\hline Model & $R$ & R Square & $\begin{array}{l}\text { Adjusted } \\
\text { Square }\end{array}$ & $\begin{array}{l}\text { Std. Error of the } \\
\text { Estimate }\end{array}$ & Durbin-Watson \\
\hline 1 &, $717^{\mathrm{a}}$ &, 514 &, 504 & 1,04258 & 1,941 \\
\hline
\end{tabular}

Sumber : data diolah, 2018

Berdasarkan tabel di atas di ketahui bahwa nilai Durbin Watson sebesar 1,941 sedangkan nilai DU sebesar 1,71517 dan DL sebesar
1,63369 maka dapat disimpulkan bahwa model regresi yang digunakan bebas dari gangguan autokorelasi 
Uji t

Hasil Uji t

\begin{tabular}{|ll|l|l|l|l|l|}
\hline Model & \multicolumn{2}{|l|}{ Unstandardized Coefficients } & $\begin{array}{l}\text { Standardized } \\
\text { Coefficients }\end{array}$ & T & Sig. \\
\cline { 3 - 5 } & & $\mathrm{B}$ & Std. Error & Beta & & \\
\hline \multirow{2}{*}{1} & (Constant) & 8,022 & 1,673 & & 4,795 &, 000 \\
& x1 &, 254 &, 080 &, 373 & 3,158 &, 002 \\
& x2 &, 381 &, 118 &, 383 & 3,241 &, 002 \\
\hline
\end{tabular}

Variabel bahan baku $\left(\mathrm{X}_{1}\right)$ :

Hasil analisis diperoleh $\mathrm{t}$ hitung sebesar 3,158 sedangkan pada taraf signifikan $\alpha=0,005$ nilai $\mathrm{t}$ tabel 1,984 dengan probabilitas (sig). sebesar 0,002 lebih kecil dari 0,005 maka $t_{\text {hiung }}<t_{\text {tabel }}$ sehingga $\mathrm{H} 0$ ditolak

Hasil analisis diperoleh $\mathrm{t}$ hitung sebesar 3,241 sedangkan pada taraf signifikan $\alpha=0,005$ nilai t tabel 1,984 dengan probabilitas (sig). sebesar 0,002 lebih kecil dari 0,005 maka $t_{\text {hiung }}<t_{\text {tabel }}$ sehingga $\mathrm{H} 0$ ditolak dan Ha di terima yang artinya variabel bahan baku secara individual mempunyai pengaruh yang signifikan terhadap target produksi Songkok Pengangsalan Lamongan

\section{Variabel $\left(\mathrm{X}_{2}\right)$}

dan Ha di terima yang artinya variabel bahan baku secara individual mempunyai pengaruh yang signifikan terhadap target produksi Songkok Pengangsalan Lamongan

\section{Uji F}

ANOVA $^{\mathrm{a}}$

Hasil Uji F

\begin{tabular}{|ll|l|l|l|l|l|}
\hline Model & & Sum of Squares & Df & Mean Square & F & Sig. \\
\hline \multirow{4}{*}{1} & Regression & 111,314 & 2 & 55,657 & 51,204 &, $000^{\mathrm{b}}$ \\
& Residual & 105,436 & 97 & 1,087 & & \\
& Total & 216,750 & 99 & & & \\
\hline
\end{tabular}

Sumber : data diolah, 2018

Hasil analisis diperoleh $F$ hitung sebesar 51,204 sedangkan pada taraf signifikan $\alpha=0,05$ nilai $F$ tabel 3,09 dengan probabilitas (sig). sebesar 0,000 lebih kecil dari 0,05 karena $F_{\text {htung }}>F_{\text {tabel }}$ maka diperoleh

\section{KESIMPULAN}

Hasil analisis uji t (parsial) variabel $X_{1}$ diproleh nilai thitung sebesar 3,158, dan $\mathrm{X}_{2}$ di peroleh $\mathrm{t}$ hitung 3,241 . sedangkan $t_{\text {tabel }}$ diperoleh asumsi bahwa Ho ditolak dan menerima Ha, sehingga teruji bahwa secara bersama-sama terdapat pengaruh antara variabel bahan baku $\left(\mathrm{X}_{1}\right)$ tenaga kerja langsung $\left(\mathrm{X}_{2}\right)$ terhadap target produksi (Y)

sebesar 1,984. Karena $t_{\text {hitung }}>t_{\text {tabel }}$ maka variabel bahan baku dan tenaga kerja langsung secara parsial berpengaruh secara signifikan terhadap target produksi songkok. 
Hasil analisis diperoleh $\mathrm{F}$ hitung (simultan) sebesar 51,204 sedangkan pada taraf signifikan $\alpha=$ 0,05 nilai $F$ tabel 3,09 dengan probabilitas (sig). sebesar 0,000 lebih kecil dari 0,05 karena $F_{\text {htung }}>F_{\text {tabel }}$ maka diperoleh asumsi bahwa Ho ditolak dan menerima Ha, sehingga teruji bahwa secara bersama-sama terdapat pengaruh antara variabel bahan baku $\left(\mathrm{X}_{1}\right)$ tenaga kerja langsung $\left(\mathrm{X}_{2}\right)$ terhadap target produksi $(\mathrm{Y})$. Karena $\mathrm{F}_{\text {hitung }}>\mathrm{F}_{\text {tabel }}$ maka variabel bahan baku, tenaga kerja langsung secara bersama-sama (simultan) berpegaruh secara signifikan terhadap target produksi.

Berdasarkan hasil perhitungan Regresi (dominan) didapatkan $\mathrm{X}_{1}=0,254 \quad \mathrm{X}_{2}=0,381$ artinya variabel yang paling dominan adalah tenaga kerja karena memiliki pengaruh yang paling besar terhadap target produksi sebesar 0,381

\section{DAFTAR PUSTAKA}

Bastian Bustami, 2013. Akutansi biaya : Edisi 4 ; Mitra Wacana Media

Ghozali 2012, Aplikasi Analisis Multivariate dengan Program IBM SPSS 2. Semarang:

Badan Penerbit-Universitas Diponegoro

Hasibuan, Malayu S.P, 2015. Manajemen, Dasar, Pengertian, dan Masalah. Bumi Aksara. Jakarta.

Handoko, T. Hani, 2015. Dasardasar Manajemen Produksi dan Operasi. Edisi I. BPFE

Yogyakarta.
Haming Murdifin. 2014. Manajemen Produksi modern. Bumi Aksara

Heizer, Jay dan Barry Render, 2011. Manajemen Operasi. Edisi 9 Buku 2. Salemba Empat. Jakarta.

Juliansyah Noor 2013 Metodologi Penelitian prenada media group

Kaljadi Mintaoem. 2013. Analisis Faktor-faktor yang Mempengaruhi Pertumbuhan Industri Kecil di wilayah Segitiga Industri di Jawa Timur (Suabaya Sidoarjo, dan Gresik). Jurnal

Mulyadi, 2014 Akutansi Biaya. Yogyakarta, STIE YKPN

Rangkuti, Freddy, 2007. Manajemen Persediaan Aplikasi dibidang Bisnis. PT. Raja Grafindo Persada. Jakarta.

Ristono, Agus, 2009. Manajemen Persediaan Edisi 1. Graha Ilmu.

Sugiyono, 2012 Metode Penelitian Kuantitatif Kualitatif dan $R \& D$. Bandung: Alfabet 
